\title{
Reducing Vibrations Generated in a Gas Turbine Model MS9001E Used in South Baghdad Power Plant Station by Improving the Design of Bearings with Damper
}

\author{
Alaa J. Abdulah*, Muhannad Z. Khalifa ${ }^{\mathbb{D}}$, Abdul Jabbar O. Hanfesh \\ University of Technology, Electromechanical Eng. Dep., Baghdad, Iraq. \\ *Corresponding author Email: eme.19.18@uotechnology.edu.iq
}

\section{H I G H L I G H T S}

- Dynamic analysis system performance for gas turbine MS9001E before and after development.

- Reduction of the first mode deformation value from $1.3134 \mathrm{~mm}$ to $0.0023 \mathrm{~mm}$ at 12 $\mathrm{Hz}$.

- Using of electrical damper instead of mechanical and suitable oil lubricant for the gas turbine.

- Replacement of the Journal bearing type with the tilt-pad bearing.

\section{A R T I C L E IN F O}

Handling editor: Muhsin J. Jweeg

Keywords:

Geometry of gas turbine

Transient Analysis

Harmonic Analysis

Strains

Vibration Frequency

\begin{abstract}
A B S T R A C T
Gas turbines are engines an energy plant makes use of for generating the rotary motion to show power generators. The gas turbine is largely a combustion engine for changing natural gas or different liquid fuels to rotational mechanical energy. Often, the gas turbine generates excessive noise or vibrations. In this work, the problem of vibrations occurrence in the gas turbine model MS9001E used in the south Baghdad power station is solved. This is done by making a groove in the bearing pad to increase the oil flow, replacing the bearing type with a tilt-pad bearing type with damper. The finite element method was used in the analysis process by ANSYS program. The results showed a decrease in the values of vibration amplitude, total deformation, stress, and strain.
\end{abstract}

\section{Introduction}

The gas unit that is used in power plants consists of three main parts, which are the air compressor, the combustion chamber, and the turbine. There are studies which have shown that the mechanical vibrations that were mentioned previously occur at varying rates in each part [1]. The gas turbine engine rotating machine has many different components, and each component must be designed to withstand different operating conditions. Any elastic machine with mass can vibrate. With A common problem with vibration is failure caused by fatigue or deformation. Vibration at the resonance frequency is the main cause of excessive deformation. If the natural frequency of the system is the same as the excitation frequency, Resonance is usually found. When resonance occurs, the vibration may increase indefinitely. The vibration will only stop because it is related to the damping of the system. This makes finding the natural frequency crucial [2]. Vibration analysis of rotating machinery in industrial plants is widely used to ensure premature fault diagnosis before these machinery malfunctions. [3].A Yasser Hammed, etc... Showed there are numerous objectives are to be fulfilled inside a standard gas turbine analysis. first of this objective is are expecting the natural frequencies and decide the mode shapes of the turbine system at the ones natural frequencies, Identify critical speeds inside or close to the operating speed range of a rotor system, make an unbalance response analysis of a gas turbine as a way to calculate rotor displacement and quantify the forces acting at the rotor helps which can be prompted because of rotor imbalance and Assess capacity dangers and operating problems in general related to the rotor- 
dynamics of a given rotor system [4]. Kulvir studied Singh Higher burn temperatures can best be reached through using the progressed materials for components along with combustor, nozzles, buckets (rotating blades), turbine wheels and spacers. These critical parts facing various operating conditions with reference to temperature, transient loads and environment. The temperature of the new gas direction parts (combustor, nozzles and buckets,) of a gas turbine is beyond the abilities of the materials used in gas turbines for this reason requiring using many advanced materials like super alloys,[5]. Ogbonnaya et al. studied Compressors associated with turbines. Surge and Stalls are two main kinds of instabilities that often occur in compressor systems that affect gas turbines. This instability often results in excessive vibration due to pressure, and commands are given through this phenomenon [6]. Mohammad h.j, etc., studied a program primarily based totally at the finite element approach is developed for rotor dynamic analysis of gas turbine rotors. The lateral vibration conduct of a certain gas turbine rotor is analyzed the usage of the developed finite detail program and coupled lateral-torsional vibration conduct of the rotor has analyzed the usage of a 3-D finite element model, [7]. The tip clearance between the compressor's rotating blades and its casing will adversely affect performance, so Cause energy loss. Over time, the gradual increase in the tip clearance is an important reason for the compressor. Performance drops. However, in modern high-efficiency compressors, the key requirements for optimal performance depend on Minimize the radial gap between the rotating blade disc and the housing. So there is a danger of contact between rotations Blade disks and enclosures have increased significantly [8]. The knowledge gap highlights that the studies dealt with the issue of the gas turbine in terms of analyzing the vibrations in the rotor and (shaftdisk-blade) as well as studying the materials and alloys that make up the gas turbine system and did not address the process of analyzing the vibration of all parts of the gas turbine and making improvements to reduce the amount of vibrations. This paper aims to make improvements to the gas turbine model MS9001E used in the South Baghdad Station to reduce vibrations. This is done by collecting data obtained from the operation and control department of the station which show the values of vibrations in the gas turbine through the monitoring screen.

\section{The gas turbine model (ms9001e)}

This model used in south Baghdad Power Plant station, this station can supply max power is about rotation speed 3000 r.p.m.

\subsection{Description of this model}

The gas turbine model (MS9001E) is a single-shaft heavy-duty gas turbine specially developed for generator drive services in the $50 \mathrm{~Hz}$ market. Its efficiency is about. It is $33 \%$ in a simple cycle and more than $50 \%$ in a combined cycle. MS9001E is consists of 17-stage compressor rotor, 3-stage turbine rotor, three bearing (the first one plain bearing is located under compressor, the second is elliptical bearing located between the compressor and the turbine, the third is tilt pad journal bearing located end of the turbine shaft).

\subsection{Vibration Rang record of Ministry of Electrical Team}

The measurements, to be made twice a month, require a wideband apparatus. They give information about the mechanical condition of the machine. Vibrations increase often means that rotating parts of the unit are in bad condition. It is important to mark the exact location of the pickups for comparative readings. Every year, take a reading during startup without firing and at stabilized speed with flames. Vibration boundaries: The maximum overall vibration velocity of the gas turbine should ever overview $(1.0 \mathrm{inch})$ per second $(25.4 \mathrm{~mm} / \mathrm{s})$ in either the vertical or horizontal direction. Corrective action should be initiated when the vibration levels exceed $(0.5$ inches $)$ per second $(12.7 \mathrm{~mm} / \mathrm{s})$ as indicated on the SPEEDTRONIC panel vibration meter [8] as shown in Figure 1.

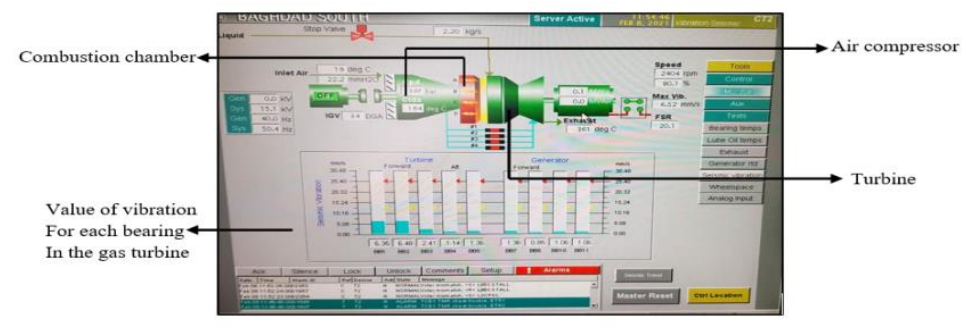

Figure 1: . Vibration value at speed $2404 \mathrm{rpm},[8]$

\section{Dynamic behavior in gas turbine}

Rotor dynamics is a branch of system dynamics, involving mechanical systems in which at least part (usually defined as the rotor) rotates with a significant angular momentum. [10] It is important to consider the dynamic characteristics of rotating machinery in the design phase to avoid catastrophic failures that may occur due to resonance conditions in operation. The dynamic analysis of rotating machinery and turbo machinery rotors has been carried out by many researchers, and the finite element method, as an effective numerical method for analyzing the dynamics of rotating machinery and mechanical structures, has recently attracted the attention of many researchers. [7] Developed a finite element model to study the dynamic characteristics of single-rotor and dual-rotor bearing turbo machinery systems. The model was analyzed to predict natural 
frequencies, generate critical speed maps, and estimate bearing stiffness. They proved that the speed ratio between the highspeed and low-speed shafts of the dual-rotor can be used as one of the design parameters of the dual-rotor system. [11]. the vibration signal is presented by the following expression [12].

$$
x(t)=A \cdot \sin (\omega t+\phi)
$$

Where $w$ is the frequency of vibration, $\phi$ is the phase and A the amplitude of vibration in micrometers [ $\mu \mathrm{m}]$.The vibration speed $v(\mathrm{t})$, Equations (2) and the vibration acceleration $\mathrm{a}(\mathrm{t})$, Equations (3) are obtained by differentiating vibration expression Eq. (1) as follows:

$$
\begin{aligned}
& v(t)=\frac{d x(t)}{d t}=A \cdot \omega \cos (\omega t+\phi) \\
& a(t)=\frac{d v(t)}{d t}=-A \cdot \omega^{2} A \cdot \sin (\omega t+\phi)
\end{aligned}
$$

\subsection{Modeling the GT}

Solidworks 2018 has been used to model the full assembly of the gas turbine MS 9001E. From the official website of GE, the captures of the gas turbine have been downloaded and used in Solidworks software to create the geometry. I used real dimensions from the gas turbine station South of Baghdad to make a scale with the captures. Many parts are model (about 38 parts) and assembled in assembly extension of Solidworks. The blades assumed to be one disk in each stage, because if we used or model all the blades that will make many elements in the mesh that are taking a too long time to solve in Ansys. Three types of bearing used in the first model and in addition two dampers used to improve the study results. The bearings created with extrude feature and divided into three parts with a split feature to assign different material for each part (White metal, Copper Alloy, and Carbon Steel). The Gas Turbine is simulated as shown in Figure 2.

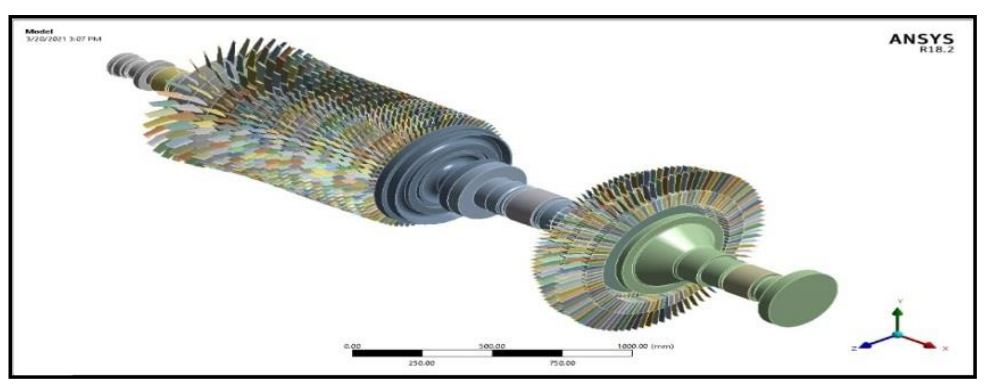

Figure 2: Geometry of gas turbine with blades

\section{Analysis process by finite element method (fem) in ANSYS}

In predicting the physical behavior of structures and systems, the finite element method (FEM) is the most common simulation technique. Because empirical solutions are typically not possible in the engineering sciences for most daily issues, numerical approaches were developed to find a solution to the particular issues' governing formulas. [9]. the three-dimensional model is applied in the analysis. The three-dimensional model of the gas turbine considering the dimension. The model was developed in SolidWorks 2018. The development model of the gas turbine blade has been sent into the FEM software called ANSYS 18.2, in which different steps of FEM are used. First, for the unstructured body, do tetrahedral elements to discretize the turbine blades, tetrahedral mesh has been used to adapt with the sharp curves and edges of the blade. Whole number of nodes and elements are 209084 and 113700 as shown in Figure 3. Figure 4 shows the chart flow of the work. It explains the work steps to create a model for the gas turbine in the soldwork program and then the process of exporting the model to the Ansys program for the purpose of analysis and obtaining the results as shown in Table 1.

Table 1: boundary condition, [11]

\begin{tabular}{ccccc}
\hline parameters & $\begin{array}{c}\text { Active. } \\
\text { power }\end{array}$ & Turbine temperature & Exit pressure of air compressor & Turbine pressure \\
\hline value & $130.14 \mathrm{MW}$ & $1025^{\circ} \mathrm{C}$ & $1013 \mathrm{kPa}$ & $1012.9 \mathrm{kPa}$ \\
\hline
\end{tabular}




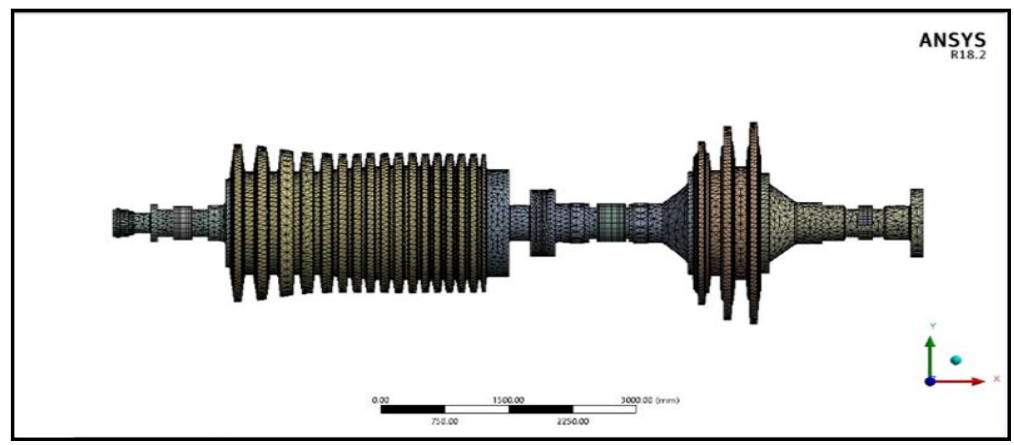

Figure 3: Meshed geometry using ANSYS

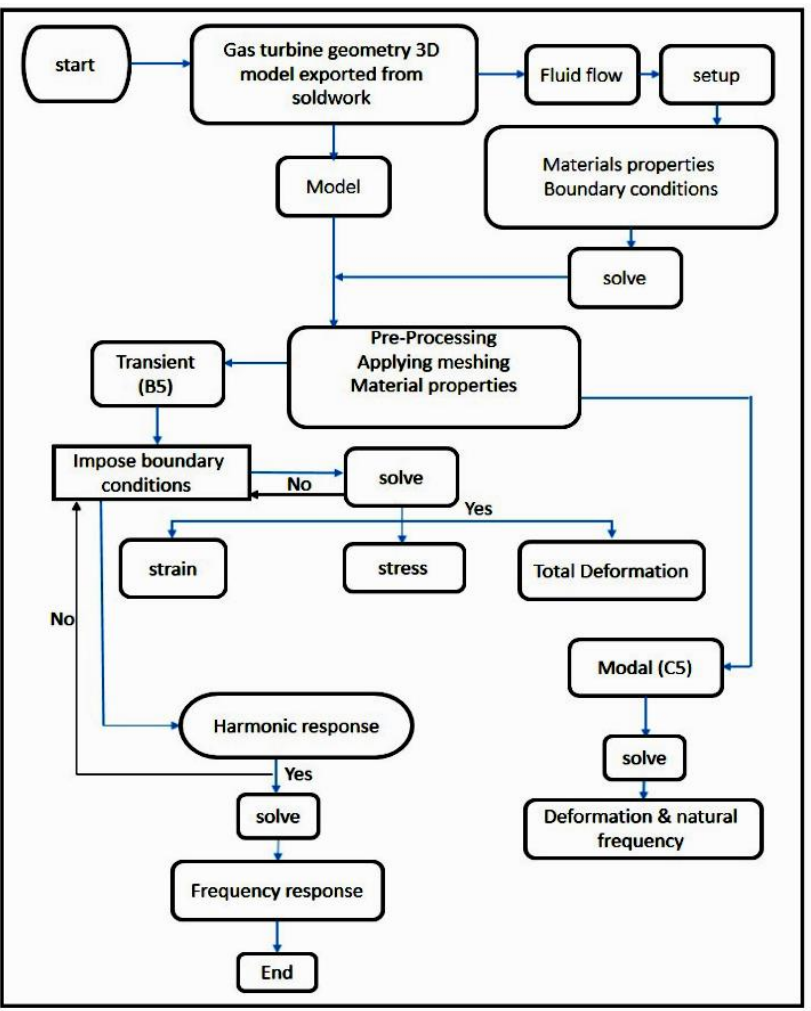

Figure 4: Chart flow of this work

\section{Results and discussion (before development)}

\section{1 (Free vibration) Modal analysis}

The gas turbine was made as geometry in the simulation for ease of solution, Figure 5 represent the results obtained for the modal analysis carried on geometry gas turbine, the total deformation about $1.3134 \mathrm{~mm}$ at frequency $12.356 \mathrm{~Hz}$. For the $1^{\text {st }}$ mode showed in Figure 5, the total deformation $2.889 \mathrm{~mm}$ at frequency $51.48 \mathrm{~Hz}$. For the $2^{\text {nd }}$. All structures have natural vibration frequencies at which they will disfigure, named resonance. Every natural frequency has a concerning mode, a shape that characterizes the structure's deformation. The lowest frequency at which deformation occur is the first mode. The first mode is what orderly defines the maximum loads in a structure or how that structure will have interaction with the other of the system around it while vibrating.

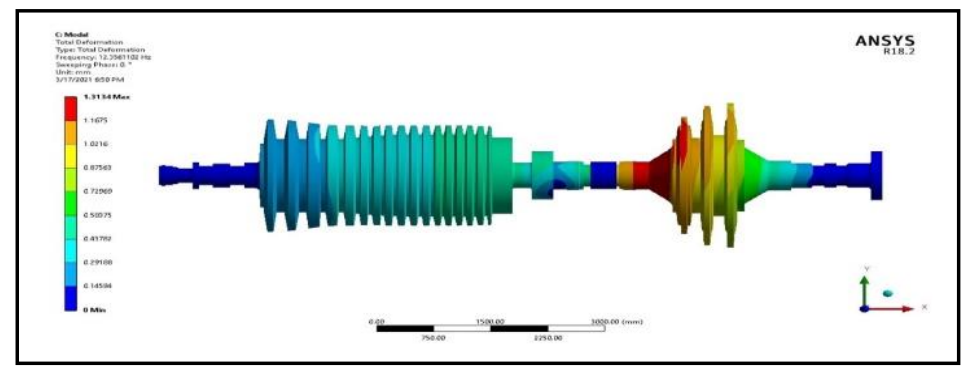

Figure 5: Deformation at frequency $12 \mathrm{~Hz}$. For $1^{\text {st }}$ mode 


\subsection{Transient Analysis}

Figure 6 showed the total deformation 2.3289mm which it was the highest value. And in Figure 7 shows the Amplitude of deformation Change with time at highest value for deformation, and the system was stability in 53.5 sec. Used to determine the dynamic response of a structure under a time-different load. The time setting for this set of analysis is such that damping effects of the structure are taken into consideration to be important Figure 8 Show the strain value 0.0122 for the equivalent elastic modulus material and, The stress value about 1128.3 Mpa by the voin-mises method for equivalent material in Figure 9.

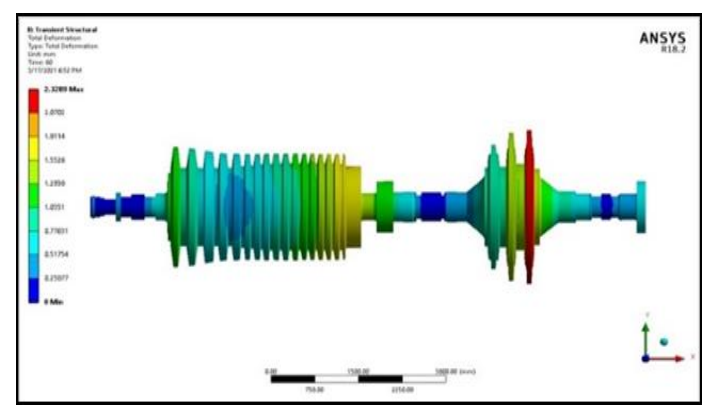

Figure 6: Total deformation in transient structure

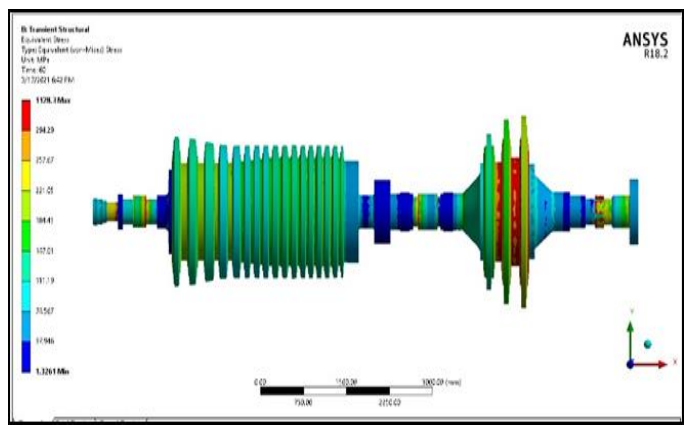

Figure 8: Show the strain value for the equivalent elastic modulus material

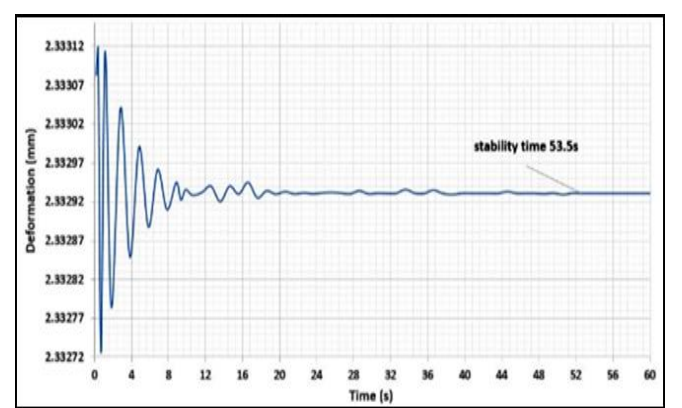

Figure 7: The amplitude value of deformation changes with time

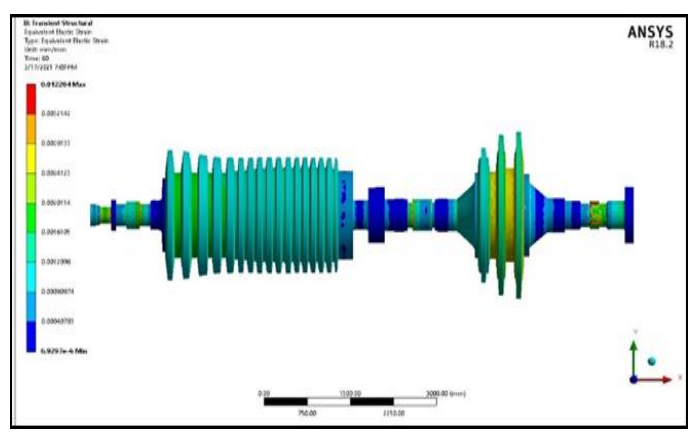

Figure 9: The stress value by the Voin-Mises method for equivalent material

\section{3 (Forced vibration) Harmonic analysis}

Figure 10 shows the total deformation $2.2 \mathrm{~mm}$ of harmonic response at frequency $50 \mathrm{~Hz}$. and in

Figure 11 shows the Amplitude of vibration change with frequency. (2.3) is higher value for amplitude of vibration at frequency $50 \mathrm{~Hz}$. Analyzing the steady-state behavior of a structure problem to cyclic loads. Transient Analysis: Defining the dynamic response of a structure under greater general time-dependent loads.

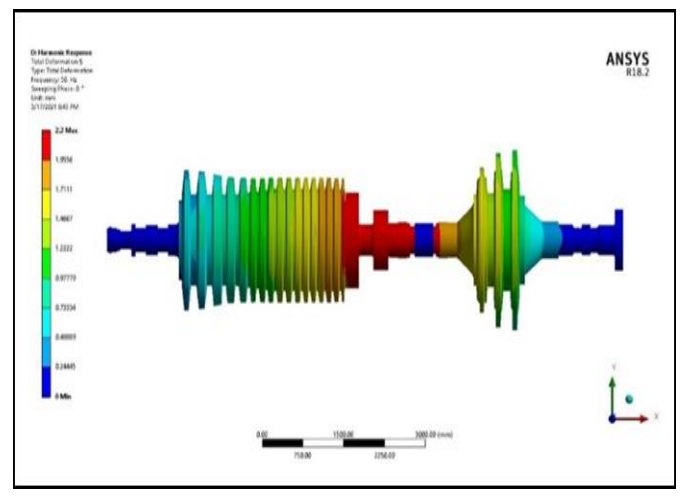

Figure 10: Harmonic vibration response at frequency $50 \mathrm{~Hz}$

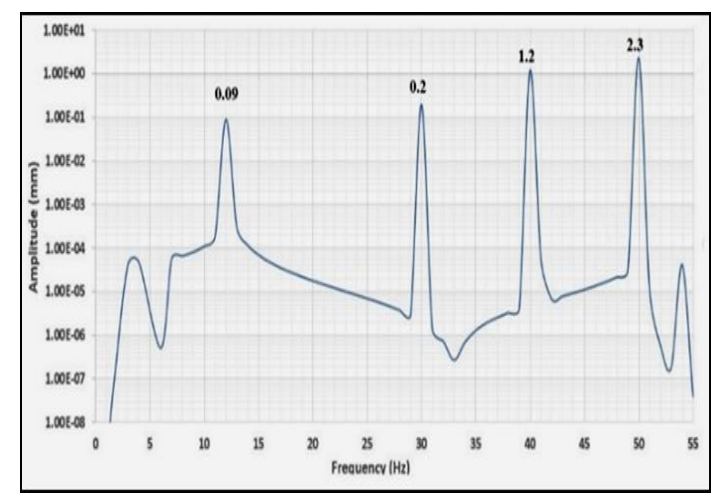

Figure 11: The amplitude of vibration value with frequency

\section{Results and discussion (after development)}

Improvements made to reduce vibrations in the gas turbine system: 
1) The type of bearings used in the system changed to tilt-pad bearing, because of their excellent stability performance. Tilt pad bearings produce, very small destabilizing cross-coupled stiffness in any case of geometry, speed, load, or operating anomaly. Table 2 shows the materials properties of bearing.

2) Using mechanical dampers under the base of gas turbine system. Which is a common solution to reduce the amount of vibrations that occur in the system.

3) Grooves have been made in the pads as shown in the Figure 12, when the rate of vibration in the gas turbine system increased, a greater amount of oil would be pumped, and these grooves were made to absorb this excess amount of oil, and it is known that the oil has the ability to absorb vibrations. Table 3 shows the dimensions of pad groove. The successful operation of the gas turbine and its driven equipment largely depends on the lubrication system. Therefore, there must be all factors that contribute to correct lubrication, and the entire system is well maintained. The type of oil used in lubrication is important because the service life of the equipment depends on the continuous supply of lubricants of appropriate quality, quantity, temperature and pressure. In this case, the service life and quality of lubricants are of vital importance to users. The lubricating oil applied for this aim is an anti-rust and anti-corrosion petroleum lubricating oil artificial hydrocarbon, which has higher high-temperature corrosion stability than global lubricating oil. The oil is a global Standards Organization Viscosity Grade 32 (ISO VG 32) oil. The properties recorded are rather typical of turbine lubricating oils a listing of recommended properties of the oil is shown in Table 4, [9].

Table 2: Properties of Babbitt alloys (White metal), [11]

\begin{tabular}{ccccccc}
\hline Properties & Alloy named & $\begin{array}{c}\text { Young's } \\
\text { Modulus } \\
\text { GPa }\end{array}$ & $\begin{array}{c}\text { Yield } \\
\text { Strength } \\
\text { MPa }\end{array}$ & $\begin{array}{c}\text { Poisson s } \\
\text { Ratio Rang }\end{array}$ & Density g/m $\mathbf{m}^{3}$ & $\begin{array}{c}\text { Melting } \\
\text { Rang , oC }\end{array}$ \\
\hline value & White Metal & $50.02-50.49$ & $120-124$ & $0.3-0.31$ & $7.27-7.37$ & $238-340$ \\
\hline
\end{tabular}

Table 3: Dimensions of pad and groove in $\mathrm{mm}$

\begin{tabular}{ccccccccc}
\hline Properties & $\begin{array}{c}\text { length } \\
\text { of arc } \\
\text { pad }\end{array}$ & $\begin{array}{c}\text { thickness } \\
\text { of pad }\end{array}$ & $\begin{array}{c}\text { thickness } \\
\text { of copper } \\
\text { alloy }\end{array}$ & $\begin{array}{c}\text { thickness } \\
\text { of white } \\
\text { metal }\end{array}$ & $\begin{array}{c}\text { width of } \\
\text { pad }\end{array}$ & $\begin{array}{c}\text { depth of } \\
\text { groove }\end{array}$ & $\begin{array}{c}\text { width of } \\
\text { groove }\end{array}$ & $\begin{array}{c}\text { width of } \\
\text { the base } \\
\text { groove }\end{array}$ \\
\hline value & $45^{\circ}$ & 43.74 & 4.5 & 4.14 & 160 & 1.24 & 4.97 & 2.48 \\
\hline
\end{tabular}

Table 4: Recommended properties of the oil

\begin{tabular}{|c|c|c|c|c|c|c|}
\hline Properties & 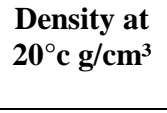 & $\begin{array}{c}\text { Specific } \\
\text { gravity at } \\
20^{\circ} \mathrm{c}\end{array}$ & $\begin{array}{c}\text { Viscosity } \\
\text { at } 40^{\circ} \mathrm{c} \\
\text { (cst) }\end{array}$ & $\begin{array}{l}\text { Viscosity } \\
\text { at } 100^{\circ} \mathrm{c} \\
(\mathrm{cst})\end{array}$ & $\begin{array}{c}\text { Acidity } \\
\text { mg koh/g }\end{array}$ & \\
\hline value & 0.8503 & 0.8514 & 31.5 & 5.1 & 0.01 & \\
\hline & & & Groove & th & $\pi^{2}$ & 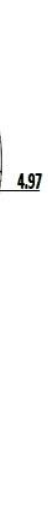 \\
\hline
\end{tabular}

Figure 12: The dimensions and geometry of the groove tile pad bearing

As a result, after making these aforementioned improvements, the pressure was increased to (1.5 bar) and the analysis process was conducted in the Ansys program on the basis of these improvements and reached:

\section{1 (free vibration) modal analysis}

Figure 13 represents the results obtained for the modal analysis carried on geometry gas turbine; the total Deformation $0.0023 \mathrm{~mm}$ at frequency $12.77 \mathrm{~Hz}$. For the $1^{\text {st }}$ mode showed in Figure 13, the total deformation $0.779 \mathrm{~mm}$ at frequency 49.88 Hz. For the $2^{\text {nd }}$. 


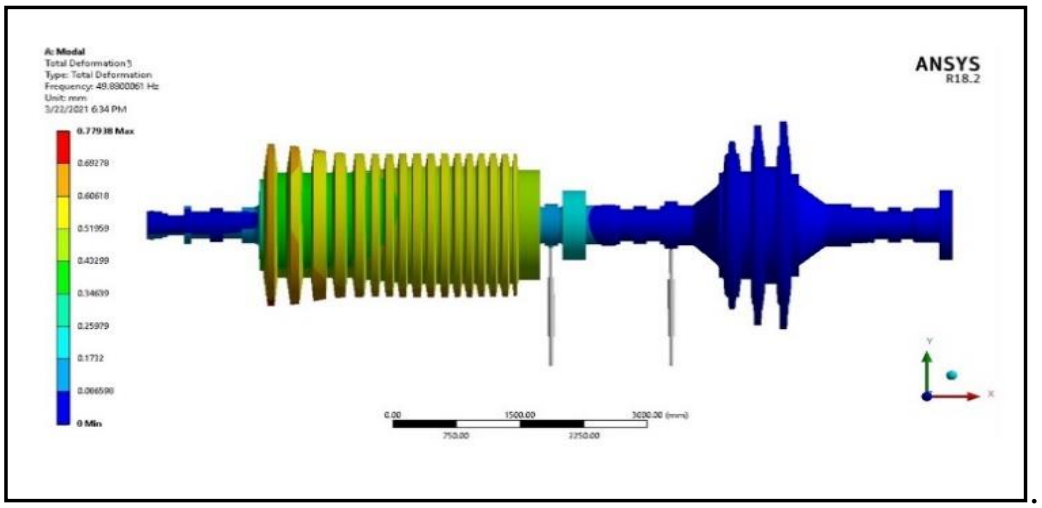

Figure 13: Deformation at frequency $12.77 \mathrm{~Hz} .1^{\text {st }}$

\subsection{Transient analysis}

Figure 14 shows the total deformation $1.465 \mathrm{~mm}$. Figure 15 shows the Amplitude of deformation Change with time at highest value for deformation and, the system was stability in $1.6 \mathrm{sec}$. Figure 16 shows the strain value 0.0055 for the equivalent elastic modulus material and, the stress value $919.45 \mathrm{MPa}$ by the Voin-Mises method for equivalent material in Figure 17.

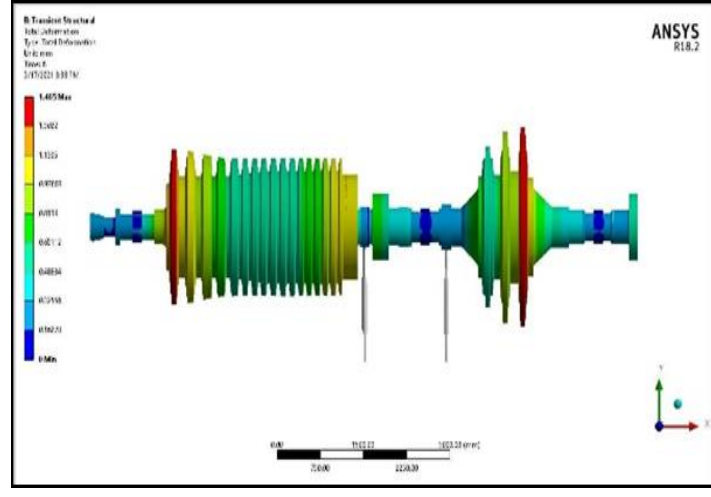

Figure 14: Total deformation in transient structure

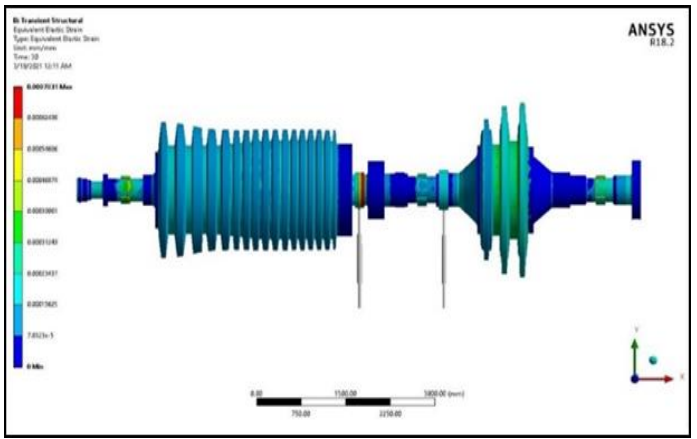

Figure 16: The strain value for the equivalent elastic modulus material

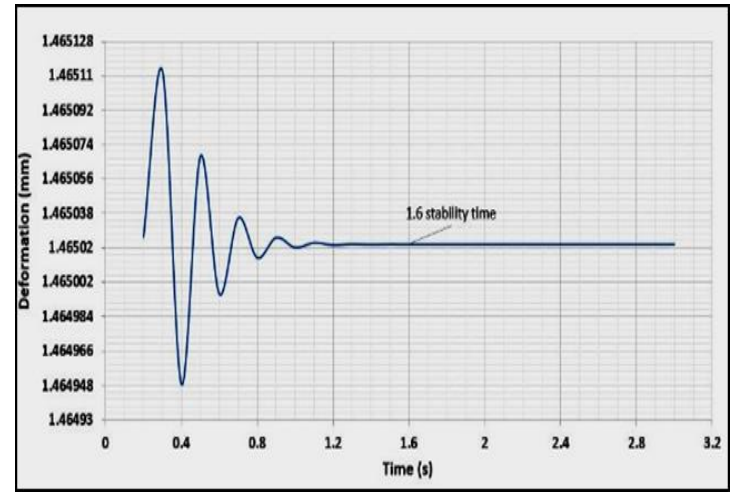

Figure 15: The amplitude value of deformation changes with time

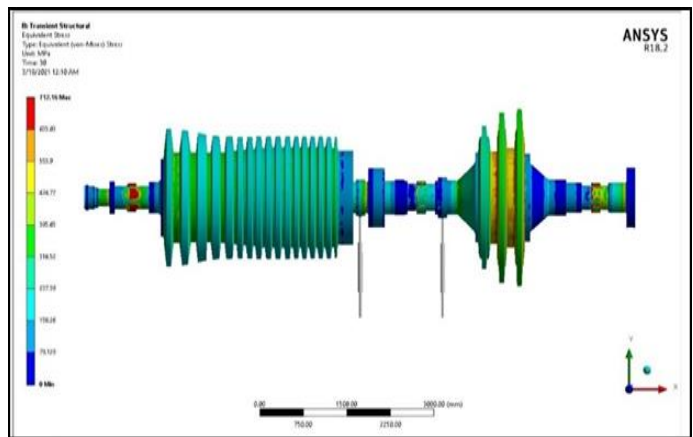

Figure 17: The stress value by the voin-mises method for equivalent material

\section{3 (Forced vibration) Harmonic analysis}

Figure 18 showed the total deformation $1.489 \mathrm{~mm}$ of harmonic response at frequency $50 \mathrm{~Hz}$. And in Figure 19 show the amplitude max. Value $1.4 \mathrm{~mm}$ when the vibration at frequency $50 \mathrm{~Hz}$. Table 5 shows the results for a gas turbine system before development (B.D.) and after development (A.D.) 


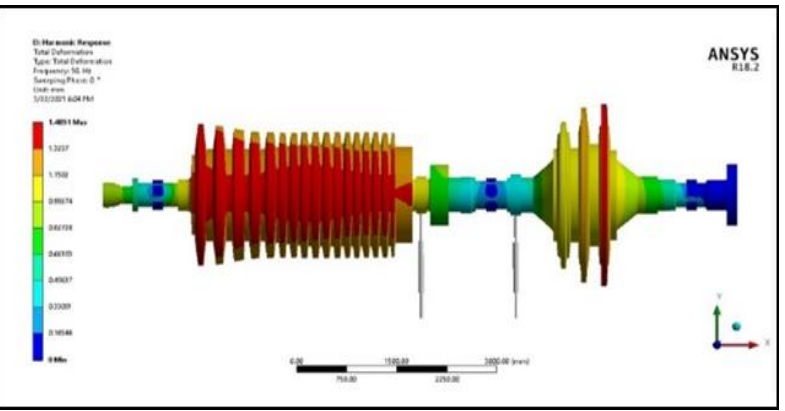

Figure 18: Harmonic response at frequency $50 \mathrm{~Hz}$

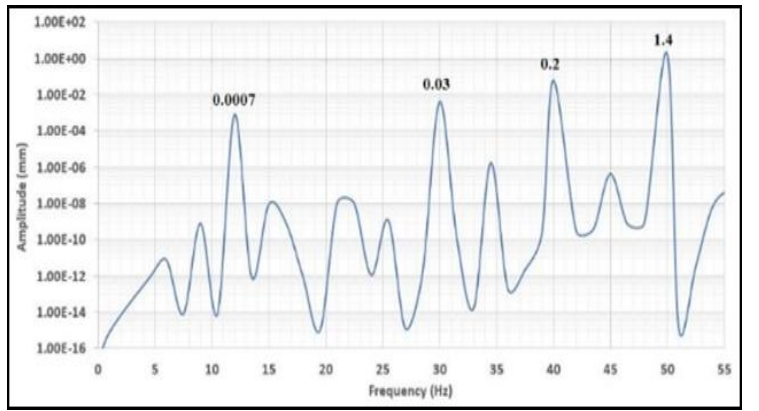

Figure 19: The amplitude of vibration value with frequency

Table 5: TABLE V: Comparison of results for a gas turbine system before development (B.D.)And after development (A.D.)

\begin{tabular}{|c|c|c|c|c|c|c|c|c|}
\hline \multirow{2}{*}{\multicolumn{2}{|c|}{$\begin{array}{c}\begin{array}{c}\text { Modal } \\
\text { analysis }\end{array} \\
\text { Deformation } \\
\text { in } 12.77 \\
\text { Hz.1st }\end{array}$}} & \multicolumn{5}{|c|}{ Transient Analysis } & \multicolumn{2}{|c|}{ Harmonic analysis } \\
\hline & & $\begin{array}{c}\text { Deformation } \\
\text { in } 49.88 \\
\text { Hz.2nd }\end{array}$ & $\begin{array}{l}\text { Stabilit } \\
\text { y time }\end{array}$ & $\begin{array}{c}\text { total } \\
\text { deformatio } \\
n\end{array}$ & $\begin{array}{c}\text { equivale } \\
\text { nt elastic } \\
\text { stress }\end{array}$ & $\begin{array}{c}\text { equivalen } \\
\text { t elastic } \\
\text { strain }\end{array}$ & $\begin{array}{c}\text { Deformatio } \\
\mathrm{n} \text { at } \\
\text { frequency } \\
50 \mathrm{~Hz}\end{array}$ & A \\
\hline $\begin{array}{l}\text { B. } \\
\text { D }\end{array}$ & $\begin{array}{c}1.313 \\
4\end{array}$ & $2.889 \mathrm{~mm}$ & $\begin{array}{c}53.5 \\
\mathrm{sec}\end{array}$ & $2.328 \mathrm{~mm}$ & $\begin{array}{l}1128 \\
\mathrm{Mpa}\end{array}$ & 0.0122 & $2.2 \mathrm{~mm}$ & $\begin{array}{l}2.3 \\
\mathrm{~mm}\end{array}$ \\
\hline $\begin{array}{l}\text { A. } \\
\text { D }\end{array}$ & $\begin{array}{c}0.002 \\
3\end{array}$ & 0.779 & $1.6 \mathrm{sec}$ & $1.465 \mathrm{~mm}$ & $\begin{array}{c}712 \\
\mathrm{Mpa}\end{array}$ & 0.0007 & $1.489 \mathrm{~mm}$ & $\begin{array}{c}1.4 \\
\mathrm{~mm}\end{array}$ \\
\hline
\end{tabular}

\section{Conclusions}

In this study, we performed Dynamic analysis system for gas turbine model MS9001E before and after development by using analytical simulation (Ansys software). By comparing the results in both cases, the following was concluded: In the model analysis, the deformation value of the first mod at frequency ( $12 \mathrm{~Hz})$ decreased to $(0.0023 \mathrm{~mm})$ after its value before development was $(1.3134 \mathrm{~mm})$, this will help reduce the stress on the system, when an excitation function interacts with the natural frequency of the structure. In the Transient Analysis, this type of analysis is used to determine the dynamic response of a structure under the action of any general time-dependent loads, after the improvements were made, the system stability time was reduced to $(1.6 \mathrm{~s})$. The deformation value of the system was decreased after making improvements to (37\%), the value of stress decreased by $36.8 \%$, while the value of strain decreased to $42.8 \%$. in the harmonic analysis, analyzing the steady-state behavior of a structure subject to cyclic loads. The deformation value decreased to $32.3 \%$, while the vibration amplitude of the system decreased to $(2.32 \mathrm{~mm})$ from $(1.4 \mathrm{~mm})$. Therefore, it is recommended to use an electrical damper instead of a mechanical and a suitable oil lubricant for the gas turbine and replace the bearing type with a type tilt-pad bearing.

\section{Author contribution}

All authors contributed equally to this work.

\section{Funding}

This research received no specific grant from any funding agency in the public, commercial, or not-for-profit sectors.

\section{Data availability statement}

The data that support the findings of this study are available on request from the corresponding author.

\section{Conflicts of interest}

The authors declare that there is no conflict of interest.

\section{References}

[1] H. J. Kadhim, Th. J. Kadhim, M.H. Alhwayzee, A Comparative Study of Performance of Al-Khairat Gas Turbine Power Plant for Different Types of Fuel, IOP Conference Series: Mate. Sci. Eng., 671 (2020). https://doi.org/10.1088/1757$\underline{899 X / 671 / 1 / 012015}$

[2] A. Y. Hammady, A. A. Ajmi, N. S. Mahmood, The Measurement and Analysis of Vibration for Gas Turbine Shaft -Rotor by Using Analytical Methods, JARDCS, J. Adv. Res. Dyn. Control Syst., 10 (2018). 
[3] B. Djaidir, A. Hafaifa, A. Kouzou, Faults detection in gas turbine rotor using vibration analysis under varying conditions, J. Theor. Appl. Mech., 55 (2017) 393-406. https://doi.org/10.15632/jtam-pl.55.2.393

[4] H. Mansoora, M. Al-shammari, A. Al-Hamood, Theoretical Analysis of the Vibrations in Gas Turbine Rotor, 3rd International Conference on Engineering Sciences IOP Conf. Series: Mate. Sci. Eng. 671 (2020). https://doi.org/10.1088/1757-899X/671/1/012157

[5] M. Dost, R. Jansen, reducing noise from gas turbines, Noise \& Vibration Worldwide, 49 (2018) $298-301$. https://doi.org/10.1177/0957456518801237

[6] S. K. Saif, G. R. Rameshkumar, Vibration Diagnosis Approach for Industrial Gas Turbine and Failure Analysis, British J. Appl. Sci. Technol., 14 (2016) 1-9. https://doi.org/0.9734/BJAST/2016/23163

[7] M.V.S. Babu1, A. Rama Krishna, K.N.S. Suman, Review of Journal Bearing Materials and Current Trends, Columbia International Publishing American J. Mate. Sci. Technol., 4 (2018) 72-83. https://doi.org/10.7726/ajmst.2015.1006

[8] E. Poursaeidi, H. Ghaemi, M. Charmchi, Effects of temperature gradient on compressor casing in an industrial gas turbine, Case Studies in Thermal Engineering, 3 (2014) 35-42. https://doi.org/10.1016/j.csite.2014.03.002

[9] Manual of General Electric(GE) Model: MS9001E Power $\quad$ Systems, 2002.http://www.fi powerweb.com/Engine/Industrial/GE-MS9001.html

[10] M.H. Jalali, B. Shahriari, Elastic Stress Analysis of Rotating Functionally Graded Annular Disk of Variable Thickness Using Finite Difference Method, Mathematical Problems in Engineering, Volume, Article ID $1871674,2018$. https://doi.org/10.1155/2018/1871674

[11] M. H. Jalali, N. Nouri, S. Ziaei-Rad, On The Finite Element Modeling Of Turbo Machinery Rotors In Rotor Dynamic Analysis, Proceedings of The Canadian Society for Mechanical Engineering International Congress 2018.

[12] B. Djaidir, A. Hafaifa, A. Kouzou, Faults detection in gas turbine rotor using vibration analysis under varying conditions, IJTAM, J. Theor. Appl. Mech., 55 (2017) 393-406 https://doi.org/10.15632/jtam-pl.55.2.393 